\title{
Sample preparation for the analysis of key metabolites from cannabinoids biosynthesis in phytoplankton using GC-MS
}

\author{
Liyun $\mathrm{Ye}^{1}$ and Suzanne Budge ${ }^{1}$ \\ ${ }^{1}$ Dalhousie University
}

September 24, 2021

\begin{abstract}
Cannabinoids biosynthesis in phytoplankton has attracted much attention due to the rapid development of genetic tools and the optimization of genetic transformation methods in microalgae. To monitor the biosynthesis process, proper sample preparation and practical instrumental methods are needed to measure the various precursors, intermediates, cannabinoids, and their degradation products. The objective of this study was to develop a sample preparation procedure for the quantification of olivetolic acid (OA), cannabigerolic acid (CBGA), cannabidiolic acid (CBDA), tetrahydrocannabinolic acid (THCA), olivetol (OL), cannabidiol (CBD), and tetrahydrocannabinol (THC) using single-quadrupole gas chromatography-mass spectrometry (GC-MS). Isochrysis galbana was used as the model matrix. After methanol extraction, samples were purified using solid phase extraction (SPE), silylated with N-methyl-N-(trimethylsilyl)trifluoroacetamide, and analyzed using GC-MS in electron ionization mode. A strong anion-exchange SPE efficiently recovered OA, CBGA, CBDA, and THCA. A graphitized carbon black SPE was necessary to purify OL, CBD, and THC. Both columns removed amino acids, sugars, polyols, and pigments from the algae extract and prepared samples that are suitable for silylation and GC-MS analysis. The total protocol, including solvent extraction, SPE, silylation, and GC-MS analysis, was validated in accordance with the ICH guidelines. Performance characteristics of our method are superior to existing protocols with similar complexity in the literature.
\end{abstract}

\section{Hosted file}

Main Text Doc.docx available at https://authorea.com/users/313517/articles/538395-samplepreparation-for-the-analysis-of-key-metabolites-from-cannabinoids-biosynthesis-inphytoplankton-using-gc-ms

\section{Hosted file}

Fig.1.docx available at https://authorea.com/users/313517/articles/538395-sample-preparationfor-the-analysis-of-key-metabolites-from-cannabinoids-biosynthesis-in-phytoplanktonusing-gc-ms

\section{Hosted file}

Fig. 2. docx available at https ://authorea. com/users/313517/articles/538395-sample-preparationfor-the-analysis-of-key-metabolites-from-cannabinoids-biosynthesis-in-phytoplanktonusing-gc-ms

\section{Hosted file}

Fig.3.docx available at https://authorea.com/users/313517/articles/538395-sample-preparationfor-the-analysis-of-key-metabolites-from-cannabinoids-biosynthesis-in-phytoplanktonusing-gc-ms 